\title{
Editorial: Psychophysiological Contributions to Traffic Safety
}

\author{
Guido P. H. Band ${ }^{1 *}$, Gianluca Borghini ${ }^{2,3}$, Karel Brookhuis ${ }^{4}$ and Bruce Mehler ${ }^{5}$ \\ ${ }^{1}$ Leiden Institute for Brain and Cognition, Leiden University Institute of Psychology, Leiden, Netherlands, ${ }^{2}$ Department of \\ Molecular Medicine, Sapienza University of Rome, Rome, Italy, ${ }^{3}$ Neuroelectrical Imaging and BCl Lab, Fondazione Santa \\ Lucia (IRCCS), Rome, Italy, ${ }^{4}$ Faculty of Behavioural and Social Sciences, Groningen University, Groningen, Netherlands, \\ ${ }^{5}$ Massachusetts Institute of Technology, Center for Transportation and Logistics, Cambridge, MA, United States
}

Keywords: attention, traffic performance, human factors, automation, psychophysiology, fatigue, workload

\section{Editorial on the Research Topic}

\section{Psychophysiological Contributions to Traffic Safety}

Research shows the dominant contribution of human factors to incidents and accidents in air (Wiegmann and Shappell, 2001), road (Petridou and Moustaki, 2000), rail (Baysari et al., 2009), and maritime traffic participation (Hetherington et al., 2006), as well as in (air) traffic control (Isaac and Ruitenberg, 2016). Operator errors are in majority associated with a non-optimal mental state, such as fatigue, drowsiness, stress, elevated mental workload, distraction from the main task, limited vigilance, and failing situation awareness (Borghini et al., 2014). In turn, most of these functional limitations can be expressed as an aberration of arousal (Collet and Musicant; Lohani et al.) and difficulties maintaining relevant information in working memory (Wu et al., 2017). In an attempt to further reduce traffic casualties, there is an increasing interest in the potential of monitoring the mental state of both professionals and non-professional users. The current Research Topic deals with the question about how mental states can be optimally tracked in simulated as well as naturalistic contexts; now and when technology progresses further toward autonomous driving.

Assessment of fitness to drive by psychometric tools (e.g., self-report such as NASA-TLX; Hart and Staveland, 1988) has serious limitations. Construct validity, sensitivity, and reliability are limited because questionnaires rely on introspection and require a subjective judgment. More importantly, these techniques are not capable of capturing real-time changes, as they are typically not administered during action. Limited gain in traffic safety can be expected from identifying risk only after the fact.

In contrast, dynamic measures have great added value in monitoring the operator's tendencies in real-time during simulated or naturalistic traffic participation. Parameters like steering variability and route compliance (e.g., Getzmann et al.) are directly relevant for operation safety. Similarly, subtle bodily motions can provide clues about the operator's behavioral and muscular tendencies as related to safety. Beggiato et al. showed an increase in backward pressure on the driver's seat when autonomous navigation led to the proximity of a truck. Ihme et al. classified video recordings of facial expressions and were able to identify muscular indicators of frustration, a predictor of less responsible driving. Previous studies have shown the value of tracking head tilt and yawning as indices of drowsiness or fatigue (Reyes-Muñoz et al., 2016).

In contrast with yawning or tightening muscles, which can be perceived as byproducts of mental state, ocular behavior is a functional characteristic that may predict performance. Eye movements reflect overt attention and as such are an index of task-relevant behavior, as defined by areas with and without relevant information. Van de Merwe et al. (2012) demonstrated the value of eye movement parameters such as fixation time, focus and entropy to index situation awareness in simulated flying. Although eye trackers record more than only gaze, other parameters are 
currently of limited value in naturalistic settings. In wellcontrolled laboratory or simulator settings, pupillometry has merit in detecting fatigue and workload (Wiegand et al., 2008). However, the pupil's strong response to variable lighting makes it virtually impossible to recognize subtle pupil dilation associated with arousal levels under naturalistic conditions. Eye blink duration, however, has successfully been linked to workload and fatigue (Benedetto et al., 2011).

In comparison with behavioral tendencies, psychophysiological and neuroimaging indicators tap even more directly into mental states during traffic participation (Van Erp et al., 2015; Borghini et al., 2017b). They have the potential to detect adverse changes before a change in the user functional state is visible in behavior. Near infrared spectroscopy (NIRS) is successful at recognizing frustration (Ihme et al.) and elevated workload (Le et al.; Scheunemann et al.) with accuracy of classification ranging from 78 to $90 \%$. Electroencephalographic activity (EEG) has traditionally been used to distinguish spectral contributions associated with higher cognitive activity (Borghini et al., 2017a; Di Flumeri et al., 2018) vs. sleep-like activity (Simon et al., 2011; Fonseca et al., 2018). EEG is superior to blood-oxygenation based recordings in its temporal resolution, which allows for the identification of transient stimulus-induced changes using event-related potentials (Brookhuis and de Waard, 2010; Rupp et al., 2019) or time-frequency analyses (Gurudath and Riley, 2014).

Mental states are not only reflected in brain activity, but also in the activity and balance of the autonomic nervous system. In particular, arousal, vigilance (Schmidt et al., 2009), and fatigue (Wang et al., 2018) can be tracked with cardiovascular recording techniques (see Lohani et al. for a review). In addition, electrodermal activity can index elevated mental workload (Mehler et al., 2012) and stress (Boucsein, 2012). As more psychophysiological signals are monitored, the reliability of

\section{REFERENCES}

Baysari, M. T., Caponecchia, C., McIntosh, A. S., and Wilson, J. R. (2009). Classification of errors contributing to rail incidents and accidents: a comparison of two human error identification techniques. Saf. Sci. 47, 948-957. doi: 10.1016/j.ssci.2008.09.012

Benedetto, S., Pedrotti, M., Minin, L., Baccino, T., Re, A., and Montanari, R. (2011). Driver workload and eye blink duration. Transport. Res. Part F 14, 199-208. doi: 10.1016/j.trf.2010.12.001

Borghini, G., Aricò, P., Di Flumeri, G., and Babiloni, F. (2017a). Industrial Neuroscience in Aviation: Evaluation of Mental States in Aviation Personnel, Vol. 18. Cham: Springer. doi: 10.1007/978-3-31958598-7

Borghini, G., Aricò, P., Di Flumeri, G., Cartocci, G., Colosimo, A., Bonelli, S., et al. (2017b). EEG-based cognitive control behaviour assessment: an ecological study with professional air traffic controllers. Sci. Rep. 7:547. doi: 10.1038/s41598-017-00633-7

Borghini, G., Astolfi, L., Vecchiato, G., Mattia, D., and Babiloni, F. (2014). Measuring neurophysiological signals in aircraft pilots and car drivers for the assessment of mental workload, fatigue and drowsiness. Neurosci. Biobehav. Rev. 44, 58-75. doi: 10.1016/j.neubiorev.2012.10.003

Boucsein, W. (2012). Electrodermal Activity. Springer Science \& Business Media. Boston, MA: Springer. doi: 10.1007/978-1-4614-1126-0_1 estimating the user's mental state can only improve (Sahayadhas et al., 2012).

Neuroscientific methods have long suffered from practical limitations, such as non-portability, intolerance to motion, invasive or intruding sensors, and computational demands that prohibited real-time use. With the advance of technology, however, more and more of these neuroscientific approaches become accessible for real-time applications, and occasionally also for improving real-world traffic safety, as in driver assistance systems. Unfortunately, not all affordable sensors are suited to monitor performance potential. Cisler et al. showed that hightech EEG recordings of midline alpha band could model speed of responding to faulty behavior of an autonomous car, but that low-tech indicators of eye gaze and heart-rate variability lacked predictive power.

The collection of papers in this Research Topic illustrates current topics in transportation research. Technology is moving forward. This introduces the challenge to maintain safety in the context of the increasingly popular, but yet imperfect operator assistance and automated driving systems. At the same time, new technology is rapidly providing new hardware, data processing algorithms and artificial intelligence that may make it more feasible and acceptable to track the operator's mental state and actively support, as needed, situation awareness. We know from the relative successes in aviation that it is possible to keep pilots aware and capable of taking over control despite extensive use of the autopilot mode. An important challenge is now to reach a similar level of capability in non-professionals, even in adverse conditions. Psychophysiological techniques can play a critical role in achieving this goal.

\section{AUTHOR CONTRIBUTIONS}

All authors listed have made a substantial, direct and intellectual contribution to the work, and approved it for publication.

Brookhuis, K. A., and de Waard, D. (2010). Monitoring drivers' mental workload in driving simulators using physiological measures. Accid. Anal. Prev. 42, 898-903. doi: 10.1016/j.aap.2009.06.001

Di Flumeri, G., Borghini, G., Aricò, P., Sciaraffa, N., Lanzi, P., Pozzi, S., et al. (2018). EEG-based mental workload neurometric to evaluate the impact of different traffic and road conditions in real driving settings. Front. Hum. Neurosci. 12:509. doi: 10.3389/fnhum.2018.00509

Fonseca, A., Kerick, S., King, J.-T., Lin, C.-T., and Jung, T.-P. (2018). Brain network changes in fatigued drivers: a longitudinal study in a real-world environment based on the effective connectivity analysis and actigraphy data. Front. Hum. Neurosci. 12:418. doi: 10.3389/fnhum.2018.00418

Gurudath, N., and Riley, H. B. (2014). Drowsy driving detection by EEG analysis using wavelet transform and k-means clustering. Proc. Comput. Sci. 34, 400-409. doi: 10.1016/j.procs.2014.07.045

Hart, S. G., and Staveland, L. E. (1988). Development of NASA-TLX (Task Load Index): results of empirical and theoretical research. Adv. Psychol. 52, 139-183. doi: 10.1016/S0166-4115(08)62386-9

Hetherington, C., Flin, R., and Mearns, K. (2006). Safety in shipping: the human element. J. Saf. Res. 37, 401-411. doi: 10.1016/j.jsr.2006.04.007

Isaac, A. R., and Ruitenberg, B. (2016). Air Traffic Control: Human Performance Factors. New York, NY: Routledge.

Mehler, B., Reimer, B., and Coughlin, J. F. (2012). Sensitivity of physiological measures for detecting systematic variations in cognitive demand from a 
working memory task: an on-road study across three age groups. Hum. Factors 54, 396-412. doi: 10.1177/0018720812442086

Petridou, E., and Moustaki, M. (2000). Human factors in the causation of road traffic crashes. Eur. J. Epidemiol. 16, 819-826. doi: 10.1023/A:1007649804201

Reyes-Muñoz, A., Domingo, M. C., López-Trinidad, M. A., and Delgado, J. L. (2016). Integration of body sensor networks and vehicular ad-hoc networks for traffic safety. Sensors 16:E107. doi: 10.3390/s16010107

Rupp, G., Berka, C., Meghdadi, A. H., Karic, M., Casillas, M., Smith, S., et al. (2019). EEG-based neurocognitive metrics may predict simulated and onroad driving performance in older drivers. Front. Hum. Neurosci. 12:532. doi: 10.3389/fnhum.2018.00532

Sahayadhas, A., Sundaraj, K., and Murugappan, M. (2012). Detecting driver drowsiness based on sensors: a review. Sensors 12, 16937-16953. doi: $10.3390 / s 121216937$

Schmidt, E. A., Schrauf, M., Simon, M., Fritzsche, M., Buchner, A., and Kincses, W. E. (2009). Drivers' misjudgement of vigilance state during prolonged monotonous daytime driving. Accid. Anal. Prev. 41, 1087-1093. doi: 10.1016/j.aap.2009.06.007

Simon, M., Schmidt, E. A., Kincses, W. E., Fritzsche, M., Bruns, A., Aufmuth, C., et al. (2011). EEG alpha spindle measures as indicators of driver fatigue under real traffic conditions. Clin. Neurophysiol. 122, 1168-1178. doi: 10.1016/j.clinph.2010. 10.044

Van de Merwe, K., Van Dijk, H., and Zon, R. (2012). Eye movements as an indicator of situation awareness in a flight simulator experiment. Int. J. Aviat. Psychol. 22, 78-95. doi: 10.1080/10508414.2012. 635129
Van Erp, J. B. F., Brouwer, A.-M., and Zander, T. O. (2015). Editorial: using neurophysiological signals that reflect cognitive or affective state. Front. Neurosci. 9:193. doi: 10.3389/fnins.2015.00193

Wang, F., Wang, H., and Fu, R. (2018). Real-Time ECG-based detection of fatigue driving using sample entropy. Entropy 20:196. doi: 10.3390/e20030196

Wiegand, D. M., Hanowski, R. J., Olson, R. L., and Melvin, W. (2008). Fatigue Analyses: From 16 Months of Naturalistic Commercial Motor Vehicle Driving Data. The National Surface Transportation Center for Excellence.

Wiegmann, D. A., and Shappell, S. A. (2001). A Human Error Analysis of Commercial Aviation Accidents in Using the Human Factors Analysis and Classification System (HFACS). Retrieved from: https://commons.erau.edu/publication/1216

Wu, Y., Miwa, T., and Uchida, M. (2017). Using physiological signals to measure operator's mental workload in shipping - an engine room simulator study. J. Mar. Eng. Technol. 16, 61-69. doi: 10.1080/20464177.2016.1275496

Conflict of Interest: The authors declare that the research was conducted in the absence of any commercial or financial relationships that could be construed as a potential conflict of interest.

Copyright (๑) 2019 Band, Borghini, Brookhuis and Mehler. This is an open-access article distributed under the terms of the Creative Commons Attribution License (CC $B Y)$. The use, distribution or reproduction in other forums is permitted, provided the original author(s) and the copyright owner(s) are credited and that the original publication in this journal is cited, in accordance with accepted academic practice. No use, distribution or reproduction is permitted which does not comply with these terms. 